\title{
Recent Advances in the Design \& Development of A Drone Used for Bio-Medical Engineering Applications : Medi-Sky
}

\author{
Dakka.Obulesu, Arunkumar G., B.P. Mishra, Spoorthi J, T.C.Manjunath
}

\begin{abstract}
The primary target or the motivation behind this paper is to build up a model of the automaton rescue vehicle to help the ambulances in sparing human lives by sending the drugs to the working environment where the influenced patients are available. A huge number of individuals bite the dust in light of rescue vehicle delays. The time taken by emergency vehicle to achieve a patient depends a great deal on the course and the traffic on the way. At the point when a medicinal crisis happens, the reaction time can have a significant effect between a real existence spared and an actual existence lost. Shockingly, ambulances can stall out in rush hour gridlock and arrive of late after the crisis call has been made, in which an unfortunate casualty may have endured a great deal of wounds and can even lose his/her life. The utilization of Unmanned Aerial Vehicles (UAV) or "Automatons" has been utilized for quite a while for a wide range of uses. The motivation behind this paper is to build up a model of automaton emergency vehicle to help the ambulances in sparing human lives. The emergency vehicle automaton enters the scene at the moment time and constant directions are given by the administrator. The automaton can gauge different constant wellbeing parameters of the patient, for example, temperature, pulse and heartbeat. The estimations of these basic parameters are then transmitted to the specialists present in a rescue vehicle. Well, the idea is to implement the same in the rural areas where penetration of healthcare is poor. The system is being designed to look after the infants and aged people in the fast-moving urban lives. The work developed in this paper along with the results shown depicts the effectivity of the methodology proposed.
\end{abstract}

Index Terms - Drone, Application, Medicine, Hardware, Software, Arduino, UAV.

\section{ORganization OF THE RESEARCH ARTICLE}

Here, the flow of the paper is as given next. A brief abstract is presented in the starting of the research article. This is trailed by the primary point or the goal of the paper in area I. The next section, i.e., the section II gives a brief overview or the introduction to the work undertaken in this paper. A brief review of the related literature, i.e., the research which was carried out by different people across the world, authors \& engineers, etc... is presented in the section III. Medical specialization aspects w.r.t. the work undertaken is presented in section IV. Section V presents a brief overview of what \& how to deliver the objective for the medical applications. Section VI gives the restrictions or the

Revised Manuscript Received on June 15, 2019

${ }^{1}$ Dr. Dakka Obulesu, Assoc. Prof., EEE Dept., CVR College of Engg., RR Dist., Telangana, India, Email : dakkaobulesh@gmail.com

${ }^{2}$ Dr. Arun Kumar G., Assoc. Prof. \& HOD, ECE Dept., JSSATE, Noida

${ }^{3}$ Dr. BP Mishra, Assoc. Prof., ECE Dept., JSSATE, Noida UP

${ }^{4}$ Spoorthi Jainar, Faculty, ECE Dept., JSSATE, Noida UP

${ }^{5}$ Dr. T.C. Manjunath, Prof. \& Head, Dept. of ECE, DSCE, Bangalore, Email : dr.manjunath.phd[at]ieee.org Mob : 9449820361 / 9591071967 nomenclature which are assumed in the research work. The proposed procedure received in the work is clarified in the area VII by taking an appropriate model. The section VIII explains the connection of the drone module in the form of a block-diagrammatic representation along with the software module (flow-chart/algorithm) that is being used for the control of the medical drone. Section IX presents the overall conclusionary remarks of the work undertaken followed by the future work $\&$ the exhaustive list of references used.

\section{ObJeCTIVE}

The main objective of building this robot will be to give the better and the faster medical facilities to all. Especially, quicker access to remote areas where healthcare problems is severely poor. The system is capable of delivering the positive results in the critical circumstances where human penetration is impossible. Being an engineer and technology enthusiast, I desire of building such products where people are impacted directly. Other objective is to test my skills and work plan. Desire to help people for social wellbeing is one of things I wants to get. I want to deliver my innovative ideas/products in the public domain to benefit them. The project delivers an idea of bringing up the medical/relief necessity in the case of emergency. This drone system powers the existing system to deliver the needs during natural calamities. Drone will be upgraded with some new components to make it more effective during night. The areas hit by natural calamities are often disconnected at the night and where human reach out is nil. The penetration of the drone-crisis system would help in delivering the needs in the catastrophe situation. The main objective is to deliver the services to unreachable [1].

\section{INTRODUCTION}

At the point when a medicinal crisis happens, the reaction time can have a significant effect between a real existence spared and an actual existence lost. With increase in population and the number of vehicles on the road, a lot of accidents occur, which leads to death of thousands of people every year. Presently envision a crisis necessity of an emergency vehicle to a spot where there is a moderate moving traffic or now and again, congested driving conditions. At the point when there is a patient who is in a pressing need of the specialist's consideration, there are chances that the patient probably won't endure the time that it takes for an emergency vehicle to reach [2].

The biggest problem is that even if the ambulance goes to a location as close as

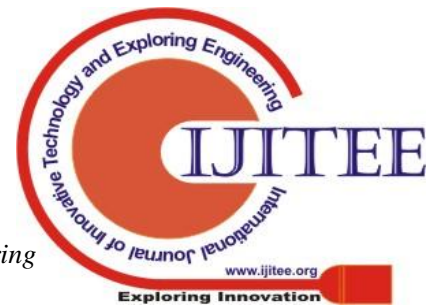


a couple of miles, it might still take about 10-15 minutes for it to reach the patient or even more. These 10-15 minutes can be vital to decide whether or not, a victim will survive. Thus, it is necessary to introduce a distinct means that would take the objective of saving human life, one step closer [3].

A drone will take off from its base location, i.e. the ambulance and can be driven by human as well as with autopilot feature. The setup consists of 4-rotating motors each of $1000 \mathrm{kv}$ which are enough to produce a decent amount of thrust which help drones to reach at a good amount of altitude. Battery of $5400 \mathrm{maH}, 11.1 \mathrm{v}$ provides a flight time of approximately 25-30 minutes [4].

The drone also consists of a GPS and a camera to increase accuracy in finding the patient's correct location. Whereas, the person in need will switch to its live location through a Smartphone featured application. Also, with the use of GPS and telemetry, the controller (service provider) can set the path to the destination [5].

The drone also comprises of various sensors which can measure patient's real time health parameters. These sensors include an ECG sensor and a heartbeat sensor. Once the drone is reached, the sensor will collect data and will convert them into electrical signals. These signals are then transmitted with the help of Wi-Fi enabled Arduino board, directly to the ambulance in the real time. The more in-depth detail will be provided in the coming sections. Furthermore, the project model aims to implement for organ transportation during organ transplantation [6].

\section{Literature SurVey}

In this section a brief review of the literature w.r.t. the work considered in this paper is being presented in a nutshell till date. Getting back in the history, different firms had tried to implement the idea for small scale purpose. In Germany, DHL Parcel has researched three generations of medical drone delivery called 3298 Parcelcopter. The first generation travelled $1 \mathrm{~km}$ to deliver blood samples across the Rhine River at Bonn. The second generation tested drone delivery of medications and other urgently needed material for three months in 2014 to Juist, one of Germany's remote North Sea Islands. The Parcelcopter travelled $12 \mathrm{~km}$ across open sea.

From January to March 2016, DHL's third generation Parcelcopter tested delivery of over 130 parcels of urgently needed medicines or sporting goods between automated Skyports in two Bavarian Alpine villages. Drone delivery took 8 minutes compared to a 30 minute road trip in winter. The time difference could be significant in a medical emergency. UPS and Zipline are working on a drone network to deliver vaccines and blood to 20 clinics in remote locations in Rwanda. Malaria, infant deaths and mothers dying in childbirth are common in Rwanda. When rabies vaccine is needed urgently, drone delivery would not be hindered by washed out roads during rainy season [7].

Only a third of Africans live within two kilometres of a road that functions year-round. Zipline drones are launched from a nest and make a delivery by dropping items with a paper parachute. After the drone returns to the nest a SIM card and new battery are inserted along with the blood or vaccines for the next delivery. Zipline drones are the size of a large dog and can carry three pounds. They can fly 45 miles in 30 minutes. Their route is tracked and changed with a tablet app.

\section{Medical Specialization}

Talking on a specific note, how can it affect the certain medical catastrophe ? A young Dutch engineer named Alec Momont tried to deliver the solution through drones. Current statistics do not reflect a promising outcome for victims of cardiac arrest outside the home. Brain death due to cardiac arrest typically occurs between 4 to 6 minutes after the incident, while the average ambulance response time sits at 10 minutes. This has led to a heart attack survival rate of only 8 percent [8].

\begin{tabular}{|c|c|c|}
\hline $\begin{array}{c}\text { Drone } \\
\text { company }\end{array}$ & Healthcare Items & Delivery Location \\
\hline Matternet & Blood, Medications & $\begin{array}{c}\text { Haiti, } \\
\text { Dominican Republic, } \\
\text { Papua New Guinea, } \\
\text { Switzerland }\end{array}$ \\
\hline DHL Parcel & Blood, Medications & Germany \\
\hline Zipline & Blood, Vaccines & Rwanda \\
\hline $\begin{array}{c}\text { Delft } \\
\text { University }\end{array}$ & Defibrillators & Netherlands \\
\hline
\end{tabular}

Table 1 : Comparison of Drone Healthcare Delivery

The use of drones to speed up emergency response time is ingenious because of their ability to bypass traffic and reach victims anywhere in a 4.6 square mile radius in 1 minute, thus cutting response time significantly. Momont claims that his drones could increase heart attack survival rates from 8 percent to 80 percent. A drone ambulance which is equipped with a medical box comprising of sensors such as temperature sensor, ECG sensor and heartbeat sensor which reaches the emergency spot earlier than the ambulance and not only measures the real time health parameters, but also transmits them to the ambulance [9].

The doctor present in the ambulance can analyze the real-time health parameters such as the condition of the heart, provided by the ECG sensor data. This enables them to prepare for the pre-medication to be given to the patient. If the condition is more critical, then the doctor can inform to the hospital well in advance to be ready for the next step in saving the patient's life. It also helps the doctor in the ambulance to come prepared by examining the patient's health parameters. This amongst other factors exemplifies how drones are a positive solution to existing problems in emergency medicine.

\section{WHAT TO DELIVER \& HOW}

The drone applications in healthcare include delivery of medicine, defibrillators, blood samples and vaccines. Well, implementation of such drones is brought up by principles of mechanical engineering, electronics engineering and electrical engineering. For designing, different types of sensors, GPS, Micro 
Controller Units (MCUs) and telemetry will be used. The detail technical implementation of the Medi Sky drone will be explained in the upcoming section [10].

\section{RESTRICTIONS}

It's not just about implementation; it's about law and order too. The United States and the UK allow their citizens to fly the drones at the permissible height of 400-500 ft. Also, drones have been criticized for inadequate regulation, safety issues and security and privacy abuse. Furthermore, irresponsible drone owners have been a nuisance in cases related to photographing accidents or fires and interfering with emergency responders. Other concerns are that people would shoot down drones and steal drone packages. These issues may hamper the growth of the project. Alec Momont, who tried to implement the same idea, was blocked due to law and orders. Hence, obstructing the technological advancement for the healthcare system [11].

\section{METHODOLOGY}

The development will require a lot mechanical, electronics and electrical engineering. Beginning with the structure of the drone, drone must be capable of lifting heavy loads. The formula to carry out the calculations for payload weight,

$$
\begin{gathered}
2(\text { wt.of drone }+ \text { wt.to be lifted })+ \\
0.2\{2(\text { wt. of drone }+ \text { wt. to be lifted })\} \\
\text { No. of electric motors }
\end{gathered}
$$

\section{Example:}

Frame : 290g

Controller Board : 30g

Motor + Propeller : $215 \mathrm{~g}$

ESC: $32 \mathrm{~g}$

MPU $6050: 15 \mathrm{~g}$

9 DoF Board : $50 \mathrm{~g}$ (GxAxM)

Range Sensor : $8 \mathrm{~g}$

GPS : $32 \mathrm{~g}$

Radio : 30g

Power Distribution Board : 28g

Battery : $425 \mathrm{~g}$

Total Wt : $1155 \mathrm{~g}$

Total Wt to be lifted : $445 \mathrm{~g}$

No. of Motors : $4(1000 \mathrm{kv})$

Note : Item weights used are taken from the different internet sources [11]

Calculation : Implies that,

$=2(445+1155)+0.2(2(445+1155)) / 4$

$=2(1600)+0.2(3200) / 4$

$=3840 / 4$

$=960 \mathrm{gf} /$ motor $($ Thrust created per motor $)(9.4 \mathrm{~N})$

Well, a hexa-copter ( 6 arms) could be a better choice over a quadcopter for lifting a heavy payload. Although, a lot depends on motors.

\begin{tabular}{|c|c|c|c|}
\hline $\begin{array}{c}\text { Drone } \\
\text { Company }\end{array}$ & $\begin{array}{c}\text { Payload } \\
\text { (KGs) }\end{array}$ & $\begin{array}{c}\text { Range } \\
(\mathrm{KMs})\end{array}$ & $\begin{array}{c}\text { Speed } \\
(\mathrm{kmph})\end{array}$ \\
\hline Matternet & 2 & 10 & 40 \\
\hline DHL Parcel & 2 & 12 & $>64$ \\
\hline Zipline & 1.4 & 72 & 145 \\
\hline Flirtey & 2 & 32 & -- \\
\hline Delft University & 4 & 12 & 97 \\
\hline
\end{tabular}

Table 2: Comparison of healthcare delivery drone payload, range \& speed

\section{BLOCK-DIAGRAMMATIC DEVELOPMENT OF THE MEDICAL DRONE (HARDWARE / SOFTWARE)}

The connection of drone module is carried out as follows in the following block-diagrammatic representation shown in the Fig. 1. The software module (flow-chart/algorithm) used for the control of the medical drone is depicted in the Fig. 2. The developmental stages consists of the following, viz., Well, ECG Sensors and other medical components will be embedded along the drone which will be further controlled by any of the MCUs [12].

\section{Hardware required}

- Drone (Motor, Frame, Esc, Battery, Propeller, A Power module

- Pixhawk Flight Controller

- Remote \& receiver

- GPS

- Telemetry

- Gimbal

- Camera

- Battery Charger

Software required

- Ardupilot

- Qconnect / Tower

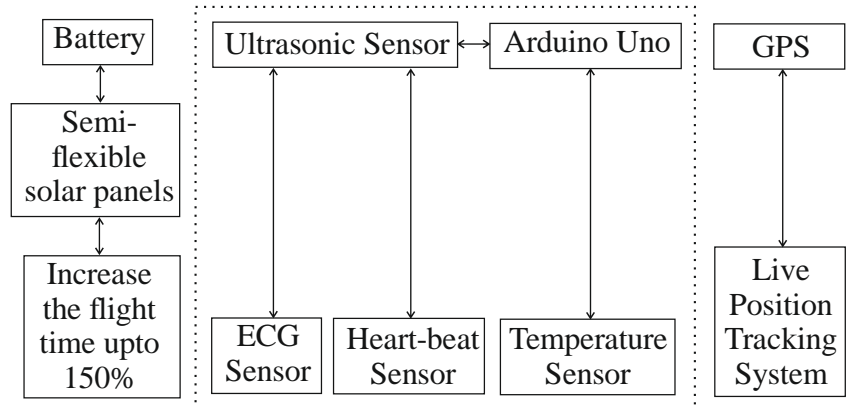

Fig. 1 : Block-diagrammatic representation of the medical drone

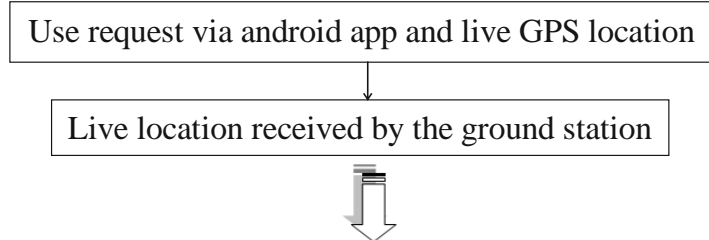

Live location received by the ground station 
DRONE

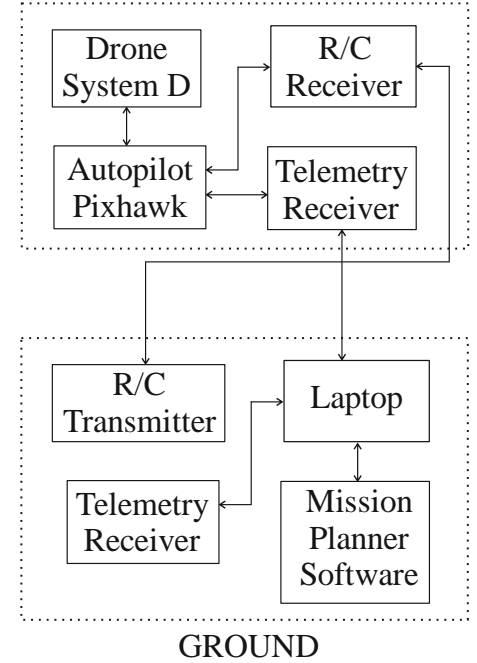

If user changes location in drone flight time

Ground station track the live location of user through app

Changing the flight path of drone midway in air according to new location

Drone reaches the updated location

Fig. 2 : Software module (flow-chart/algorithm) used for the control of the medical drone

\section{COnClusion}

The system will deliver a very positive result to the people in need. The system is designed to help the needy with better medical facilities. Well, this system covers all sought of age group. Medi-Sky covers rural as well as urban region. Catastrophic situation don't cover any specific age group, income levels or geography. The system is under development and will bring the affirmative results and help a lot of people. The aim is to design a drone carrying the medical applications. These medical applications will help to benefit the needy.

In today's world, there is a lot of traffic on roads which leads to congestion in the whole city. So, in the time of emergency crisis situation, an ambulance which travels via road may not be able to reach the destination in time and the patient might lose his or her life. Thus, it is necessary to introduce a distinct means that would take the objective of saving human life one step closer. A drone or a quadcopter takes aerial route and is not driven by human. Using more number of motors and propellers will produce more thrust, this is the main highlight of the work [13].

\section{FUTURE WORK}

A lot further headways should be possible. The automaton can be made self-ruling. The GPS module can be utilized to gain the area of the objective and AI can be utilized to assist the automaton with calculating most brief way to achieve the goal. A camera can be actualized in the automaton with the goal that the present circumstance can be seen by the specialist in the emergency vehicle. A considerably more powerful automaton can be produced for doing this particular activity. Use of automatons in the restorative business is a creating field which has a colossal extension for further research.

\section{A C K NOWLED G M E T}

The people responsible for the creation of this paper likes to thank all the officials of CVR College of Engg., JSS Academy of Tech. Edn., Noida, UP \& DSCE in all respects for helping them to publish the paper.

\section{REFERENCES}

1. Vangara Vamsi Krishna, Shivang Shastri, Shubhra Kulshrestha, Mrs. A Mariajossy, "Design of Drone Ambulance", International Journal of Pure and Applied Mathematics, Volume 119 No. 15 2018, 1813-1818, ISSN: 1314-3395 (on-line version), url: http://www.acadpubl.eu/hub/ Special Issue.

2. Josefin Lennartsson, "Strategic Placement of Ambulance Drones for Delivering Defibrillators to out of Hospital Cardiac Arrest Victims", KTH, School of Architecture and the Built Environment (ABE), Urban Planning and Environment, Geoinformatic, 2015.

3. Josephin Arockia Dhivya, Dr. J. Premkumar, "Quadcopter based technology for an emergency healthcare," 2017 3rd International Conference on Biosignals, images and instrumentation (ICBSII), 16-18 March 2017.

4. Tan Han Rong, Ronald, "Collaborative UAV study ," National University of Singapore, 2009.

5. Farin, N. Sharif, S. and Mobin, I, “An Intelligent Sensor Based System for Real Time Heart Rate Monitoring”, (HRM), Intelligent Control and Automation, 7, 55-62,May 2016.

6. www.radio-electronics.com

7. www.ni.com

8. www.wikipedia.org

9. Trio Adiono; Renitia Murti Rahayu, "Zigbee baseband hardware modeling for Internet of Things IEEE 802.15.4 compliance”, 6th International Conference on Electrical Engineering and Informatics (ICEEI), 2017.

10. http://pharpoint.com/wp-content/uploads/2013/06/Ambulance-Drones. pdf

11. https://scholarspace.manoa.hawaii.edu/bitstream/10125/41557/paper0 408.pdf

12. https://acadpubl.eu/hub/2018-119-15/4/794.pdf

13. http://www.goelectromech.in/doc/Ambulance\%20Drone\%20Support\% 20System\%20(ADSS).pdf

\section{AUTHORS PROFILE}

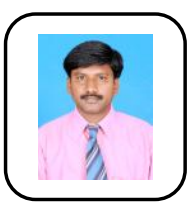

Dr. D. Obulesu received his B.E. degree in Electrical and Electronics Engineering from STJ Institute of Technology, Karnataka University, Karnataka, India, in 2000 and his M.Tech in Power Electronics and Drives from Dr. M.G.R. University in 2005. He received his $\mathrm{PhD}$ degree in Electrical Engineering from JNTU, Hyderabad, India, in 2015 . He has teaching experience of nearly 15 years. Currently, he is working as Associate Professor in CVR College of Engineering, Telangana, India, in the Department of Electrical \& Electronics Engineering. He has published a number of research papers in various national and international journals and conferences. His areas of interests are neural networks, fuzzy logic, artificial intelligence, power electronics, MATLAB, FACTS, and so on.

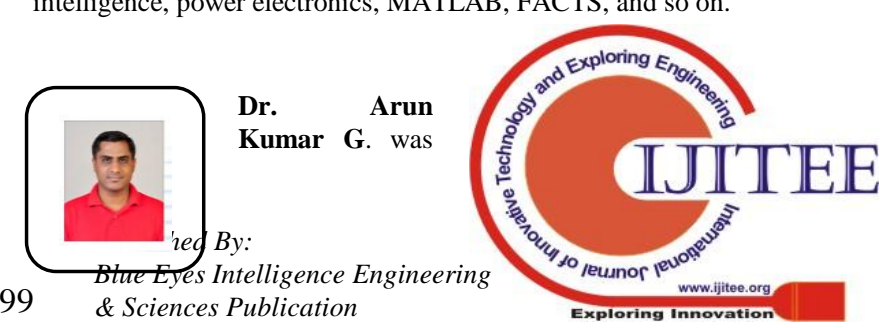


born in Davanagere, Karnataka, India on Oct. 15th, 1981 \& received the B.E. Degree (Bachelor of Engg.) from STJ Institute of Technology, Ranebennur in Karnataka in the year 2004, M.Tech. degree in Digital Communication \& Networking from the prestigious UBDT College of Engg., Davanagere in the year 2008 and completed his Ph.D. in Electronics in Visvesvaraya Technological University, Belgaum in the year 2016. He has got a teaching $\&$ administrative experience of more than 12 years in engineering colleges in Karnataka. He has written a number of notes in various subjects as Basic Electronics, AEC, Power Electronics, Communications \& his notes are widely famous all over the country. He has also published 3 text books. Currently, he is working as Associate Professor in the ECE Dept. of JSS Academy of Technical Education @ Noida in Uttar Pradesh, India. He has attended a number of certificate courses, workshops, FDPs, Symposiums, etc. He has published more than 50 papers in various subjects of engineering field. His current areas of interest are control systems, power electronics, basic electronics, micro-controllers, embedded systems, communications etc....

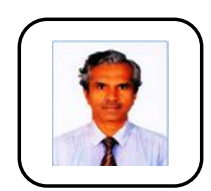

Dr. T.C. Manjunath received the B.E. Degree (Bachelor of Engg. in Electrical Engg.) from R.V. College of Engg. (Bangalore Univ.) in the year 1989, M.E. degree in Automation, Control \& Robotics from the prestigious 100 year old Govt.'s LD College of Engg., (Gujarat Univ., Ahmadabad) in the year 1992 and Ph.D. in Systems \& Control Engineering from the prestigious Indian Institute of Technology Bombay (IIT Bombay) in the year 2007 respectively. He has got a teaching (academic), research \& administrative experience of nearly $32+$ years in various engineering colleges all over the country (Karnataka, Gujarat, Maharashtra). He has published more than $600+$ papers in various National, International Journals and Conferences in India \& abroad and published more than a dozen textbooks.

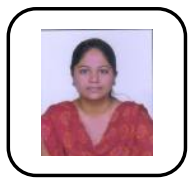

Spoorthi Jainar was born in Harihar, Karnataka, India \& received the B.E. Degree (Bachelor of Engg.) from Shri Taralabalu Jagadguru Institute of Technology in Ranebennur District of Karnataka in the year 2004, M.Tech. degree in Digital Communication \& Networking from the prestigious Shri Taralabalu Jagadguru Institute of Technology in Ranebennur District of Karnataka in the year 2010 and is pursuing her Ph.D. in Electronics in Visvesvaraya Technological University, Belgaum since 2016. She has got a teaching \& administrative experience of more than 5 years in STJIT, KLECET, RYMEC, GMIT in Karnataka. She has also published a number of research papers on various topics in different national \& international conferences / journals across the world. Currently, she is pursuing Ph.D. in VTU in Karnataka, India and at the same working as an Asst. Prof. in the ECE dept of JSS Academy of Technical Education, Noida, Uttar Pradesh since 2018. She has attended a number of certificate courses, workshops, FDPs, Symposiums, etc. Her current areas of interest are communications, signal processing, image \& speech processing, etc...

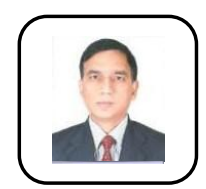

Dr. Bajarang Prasad Mishra (Ex IAF) was born in India. He did his B.E. in Electronics \& Communication Engg., from the prestigious Institution of Engineers (India), Calcutta in the year 1998. He did his MBA in Marketing @ CSJM University, Kanpur in the year 1999. $\mathrm{He}$ dis his M.Tech. from the prestigious Motilal Nehru National Institute of Technology, Allahabad with First class with Distinction (Final CGPA-8.4) in the specialization of Control \& Instrumentation in the year 2004. He completed his Ph.D. doctorate in the field of signal processing in the year 2015 from the Jamia Millia Islamia (JMI), a Central University from North Delhi, India \& worked on IVC for Mobile Phones in the presence of background noise. He has got a 20 Years regular distinguished service in IAF (Indian Air Force) \& worked on the maintenance of air-borne/ ground Nav-aid radio equipments at various Air Force units from 1985 to 2005 . He worked in GNIT, Greater Noida at the levels of Assoc. Prof., in the dept of EC/EE/EI for a period of more than 10 years from 2005 to 2016 \& taught Control System / Communication Engg / DSP / Soft Computing / QM / NCER and further also worked as Dean (A), Registrar, Head, Dy. Registrar (A) - EC. Currently, he is working as Associate Professor in the Dept. of E \& C Engg. of JSSATE, Noida since Oct. 2016. His field of interest is the air borne vehicles, communications, signal processing, etc. 